\title{
Flow patterns over vegetation patches in the natural channel
}

\author{
Yonguk $\mathrm{Ryu}^{1}$, Joongu Kang ${ }^{2}$, Un $\mathrm{Ji}^{2, *}$, Sanghwa Jung ${ }^{2}$, Changlae Jang ${ }^{3}$ and Ellis Penning ${ }^{4}$ \\ ${ }^{1}$ Pukyong National University, Busan, Rep. of Korea \\ ${ }^{2}$ Korea Institute of Civil Engineering and Building Technology, Goyang, Rep. of Korea \\ ${ }^{3}$ Korea National University of Transportation, Chungju, Rep. of Korea \\ ${ }^{4}$ Deltares, Delft, The Netherlands
}

\begin{abstract}
This study carried out experiments to investigate the effects of vegetation patches of rooted willows on the flow pattern. Stream-scale experiments on vegetated flows were performed for various hydraulic conditions: emergent and submerged conditions of vegetation. Vegetation patches were arranged by alternative bar formation and the flows in vegetated and non-vegetated sections were compared. Three-dimensional flow velocity was measured by ADV (Acoustic Doppler Velocimeter) and ADCP (Acoustic Doppler Current Profiler). Vertical, cross-sectional, and longitudinal velocity distributions were provided for different hydraulic conditions at various points. Flow velocities through the sparse patch were similar to those of non-vegetation area for low flow condition of emergent vegetation. Dense and submerged vegetation produced more complicated and non-uniform flows over the cross-sections of vegetation patches.
\end{abstract}

\section{Introduction}

Vegetation in rivers is a factor contributing to hydraulic roughness and morphodynamics in the fields of hydraulic engineering. Especially in small size streams vegetation may cause significant changes to bed morphology of channel. Vegetation roughness has been an important topic for several decades because of the effects vegetation can have on water conveyance. In general, hydraulic roughness is considered one of the most uncertain aspects of river modelling. Due to the ecological features of vegetation, furthermore, the roughness of vegetation does not only depend on the species, but also on the density, seasonal variability, patchiness, undergrowth, stage and so on. For example, when plants grow in floodplains of regulated rivers, they can seriously hamper conveyance of water during high discharge conditions [1]. During these conditions, safety against flooding may be at risk, possibly affecting thousands of people and businesses in the areas adjacent to the rivers. Proper modeling of flow resistance of vegetated channels and floodplains is of practical importance. By increasing local hydraulic roughness, vegetation reduces flow velocity and bed-shear stress, increasing local sedimentation. Therefore, it is important to consider the presence of vegetation in numerical modeling. However, the assumptions in the models are not always accurate and need to be calibrated. The roughness factor of the

* Corresponding author: jiun@kict.re.kr 
vegetation is usually treated as a constant, but vegetation roughness is affected by vegetation species, density, patchiness and seasonality.

There have been many studies have been conducted for the relationship between flow resistance and the distribution of vegetation [2-5]. Several methods to describe the relationship between flow resistance and vegetation mostly have been proposed and compared with only flume scale data. Therefore, the use of stream-scale experiment data for calibrating and validating numerical models is the first requirement for practical advance.

The objective of this study is to investigate the hydraulic characteristics using velocity data for better understanding of ecohydraulic processes. This study is part of the research acquiring stream-scale experiment data of vegetated flows and linking experimentally gathered data to numerical models. This paper presents the limited results of a study focused on velocity measurement in the stream-scale channel characterized with vegetation patches of rooted willows. For the objective, this study analyzes vegetation effect on changes in velocity distribution due to high and low densities of plants for emergent and submerged cases in the stream-scale channel.

\section{Experiemtal setup}

\subsection{Experiment channel and conditions}

Stream-scale experiments for vegetated flows have been performed in KICT-REC (Korea Institute of Civil Engineering and Building Technology - River Experiment Center) that is located in Andong city, Korea. The REC is capable of conducting real scale tests with three prototype channels (about $600 \mathrm{~m}$ long and $11 \mathrm{~m}$ wide) and large capacity pump facility (maximum flow rate of $10 \mathrm{~m}^{3} / \mathrm{s}$ ).

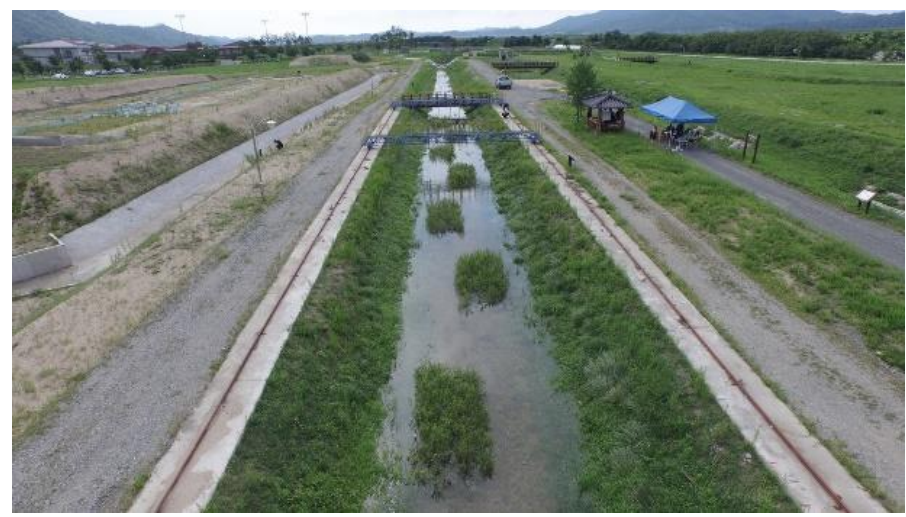

Fig. 1. Vegetated channel in the REC.

The channel section used for this study is $60 \mathrm{~m}$ long with a trapezoidal cross-section of $3 \mathrm{~m}$ bottom width and $11 \mathrm{~m}$ top width as shown in Figure 1. A bank slope was 1:1.5 (V:H) and a bed slope was $1 / 1,000$. The median size of bed materials was about $0.8 \mathrm{~mm}$. The willows were planted 1 year ago to form the alternative bar shape of vegetation patches of 4 $\mathrm{m}$ long and $1.5 \mathrm{~m}$ wide as shown in Figure 2. Seven vegetation patches arranged in an alternative bar formation. When the willows were planted, a diameter of stems was $1 \mathrm{~cm}$ and the average height was around $0.7 \mathrm{~m}$. They grew up to $1.38 \mathrm{~m}$ when the experiments started. The rooted willows were used for the experiments with two types of vegetation 
density. The dense patches were built with $38 \mathrm{stems} / \mathrm{m}^{2}$ and the density of the sparse patches was $10 \mathrm{stems} / \mathrm{m}^{2}$.

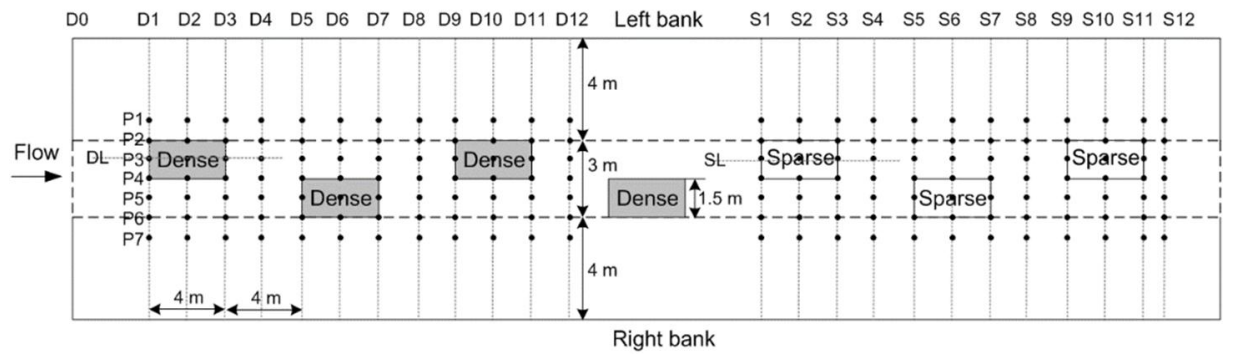

Fig. 2. Sketch of vegetation patches and measurement points.

Three different hydraulic conditions were applied for the experiments (Table 2). Flow discharge and water depth were controlled to create emergent, partially submerged, and fully submerged conditions of vegetation.

Table 1. Experimental conditions.

\begin{tabular}{|c|c|c|}
\hline Case & Flow discharge $\mathbf{( \mathbf { m } ^ { \mathbf { 3 } } / \mathbf { s } )}$ & Water depth $\mathbf{( m )}$ \\
\hline 1. Emergent & 0.5 & 0.6 \\
\hline 2. Partially submerged & 2.4 & 1.0 \\
\hline 3. Submerged & 3.7 & 1.1 \\
\hline
\end{tabular}

\subsection{Flow measurements over vegetation patches}

Three-dimensional flow structure was measured with ADV (Acoustic Doppler Velocimeter) and ADCP (Acoustic Doppler Current Profiler) as shown in Figure 3. For the emergent condition of Case 1, ADV use was only possible for measuring flows over the vegetation patches. However, in the main flowing channel of non-vegetation section, ADV and ADCP were both applied. For partially submerged condition of Case 2, it was possible to use ADCP as well as ADV for measuring flows in the vegetation patches, but a discrepancy between measured values by ADV and ADCP was observed due to a disturbance by bending and wavering of willows. During the experiment of Case 3, ADCP was also used for measuring longitudinal velocity distributions (Sections DL and SL in Figure 2). For the experiments of Cases 1 and 2, ADV measurements were performed in total 7 points for each cross-sections with a $5 \mathrm{~cm}$ interval of a vertical direction for each points. Crosssectional points for ADV measurement of Case 3 were increased by 23 points.
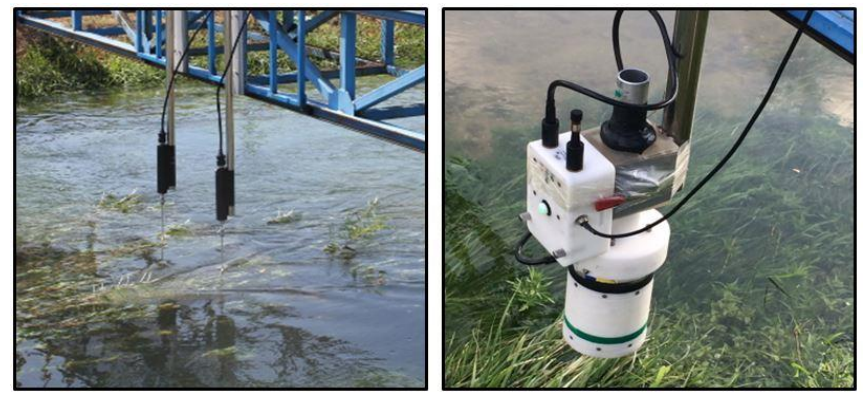

Fig. 3. Flow measurements with $\mathrm{ADV}$ and $\mathrm{ADCP}$ over the vegetation patches. 


\section{Preliminary results}

This paper provides the preliminary experiment results. The analysis of the data from ADV and ADCP measurements was made regarding the water depth conditions.

\subsection{Emergent condition}

Measurements of the mean velocity profile across the channel for the emergent condition represented low velocity over vegetation patches and higher velocity in the open channel of non-vegetation area. Figure 4 shows the vertical distributions of time-averaged stream-wise velocities at various locations. By comparison of velocity profiles of P3 and P5 in Section D2 of first dense patch, maximum velocity measured by ADV was decreased by $50 \%$ due to dense vegetation (Figures. 4a, b). However, at sparse patch, a different trend was observed in stream-wise velocities. At Locations of P3 and P5 of Section S2, maximum velocities measured by ADV were similar because of larger spacing of sparse vegetation (Figures. 4c, d).

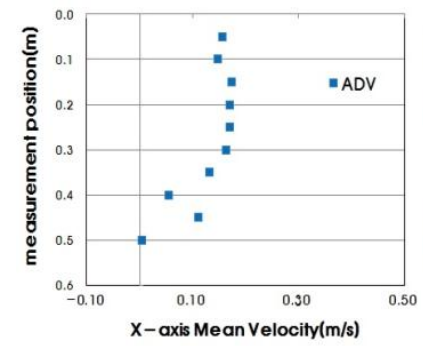

(a) D2-P3

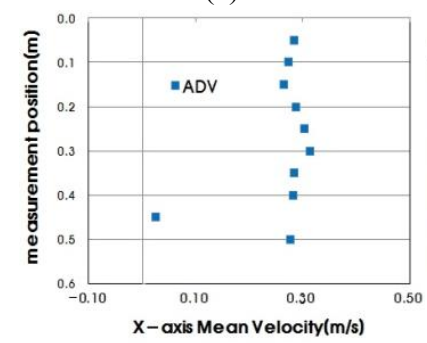

(c) S2-P3

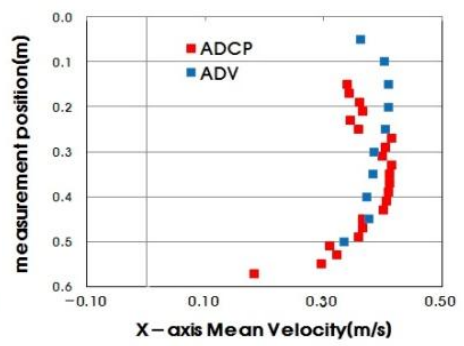

(b) D2-P5

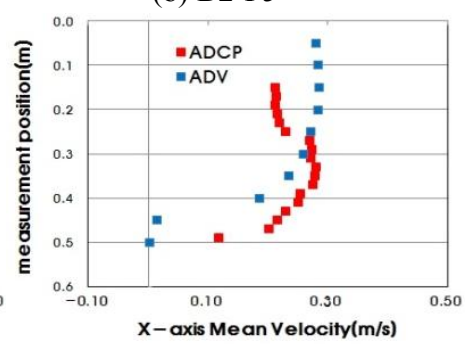

(d) S2-P5

Fig. 4. Vertical velocity distributions at different locations for the emergent condition.

\subsection{Partially submerged condition}

Flow patterns of partially submerged condition became more complicated due to the increased water depth in the vegetation zone. Generally velocities within the vegetation zone are reduced (Figure 5). The distributed areas with reduced velocities which are lower than $0.2 \mathrm{~m} / \mathrm{s}$ are dissimilar for dense and sparse vegetation. It could result from the irregularity of density and flexibility of rooted vegetation in the sparse vegetation with complicated flow characteristics. The velocity gradients in the vegetation patches (D2-P3, S2-P3) are larger than the velocity gradients of non-vegetation area (D2-P5, S2-P5) as shown in Figure 5. Dense vegetation generated more complicated and scattered patterns of vertical velocity distribution. Stream-wise velocities at various locations in the dense and sparse patches were reduced because the drag exerted by the plants decreased the flow within the vegetation. 


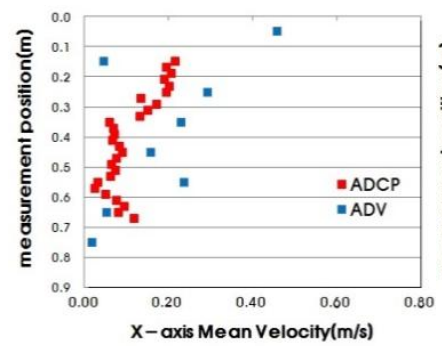

(a) D2-P3

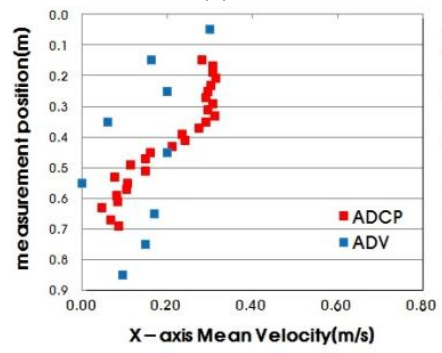

(c) S2-P3

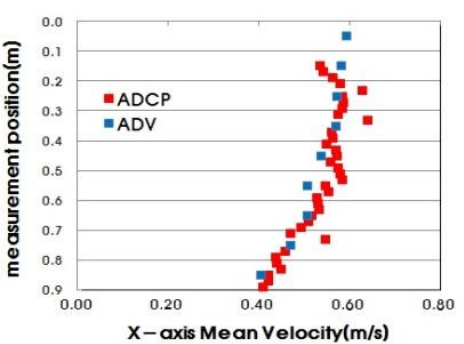

(b) D2-P5

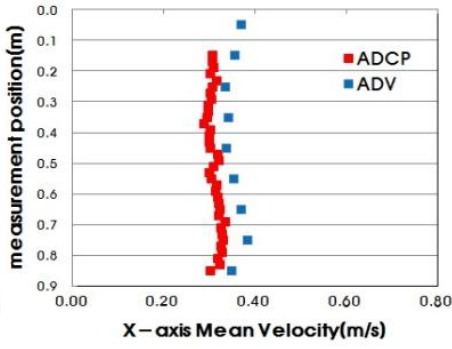

(d) S2-P5

Fig. 5. Vertical velocity distributions at different locations for the partially submerged condition.

\subsection{Submerged condition}

The large scale experiment of the submerged condition was performed to observe flow patterns of fully submerged condition for vegetation patches with high and low densities. Especially, for this case, the vertical velocity distributions were compared with the approach velocity of Section D0. Velocity gradients in a vertical direction became larger than emergent condition because of the interaction between the flow through the vegetation and the deflected flow passing above the vegetation. In this experiment, the flow velocity through the dense vegetation of D2-P3 at the location of $0.8 \mathrm{~m}$ below the water surface was approximately less than $0.2 \mathrm{~m} / \mathrm{s}$, which was twice smaller than that of the approach velocity. The discrepancy between the velocity passing through the dense vegetation and the approach velocity became large between $0.4 \mathrm{~m}$ and $0.8 \mathrm{~m}$ below the water surface.

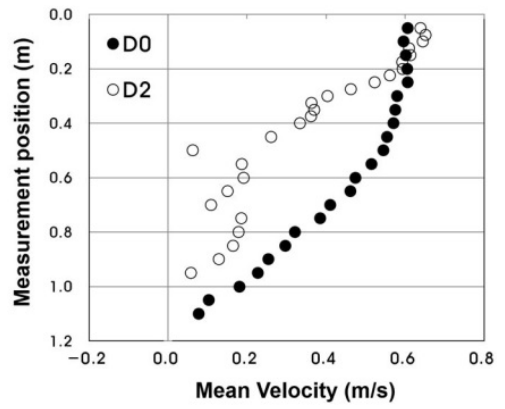

(a) D2-P3

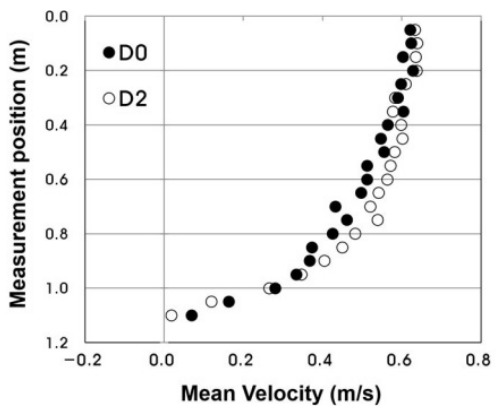

(b) D2-P5

Fig. 6. Vertical velocity distributions at different locations for the submerged condition. 


\section{Conclusions}

This study investigates vegetated flows with high and low densities of willows in streamscale experiments using ADV and ADCP measurements. The results obtained so far show that the flow velocity in the channels section is larger than that in the vegetation sections except the emergent case. The flows under the emergent case gives similar magnitudes regardless of vegetation. We may find what causes no influence from the vegetation condition. From the partially submerged condition, the reduction rate of the flow velocity due to the vegetation appears to be relatively large over the dense patches while the scattered velocity profile in the vegetation section does not give a certain pattern depending on the vegetation density. The velocity profiles given in this study is of a mid point in the channel section and vegetation section either cross-sectionally or longitudinally. More velocity profiles over the patches need to be studied. Like the submerged conditon showing the flows of the cross-sections between with and without a vegetation patch, comparing flow profiles over the vegetated cross lines with those upstream or downstream could give a better interpretation. In addition, the water depth difference of $10 \mathrm{~cm}$ made the vegetation fully submerged. Especially the flows near the free surface could be interesting between two cases. More results will be presented.

\section{Acknowledgement}

This research was supported by Korea Institute of Civil Engineering and Building Technology (KICT 2018-0087).

\section{References}

1. T. Tsujimoto, J. Hydr. Res., 37, 789 (1999)

2. M.J. Baptist, V. Babovic, J. Rodriguez Uthurburu, M. Keijzer, R.E. Uittenbogaard, A. Mynett, A. Verwey, J. Hydr. Res., 45, (2007)

3. A. Crosato, M.S. Saleh, Ear. Sur. Proc. Land. 36, 711 (2011)

4. W.M. van Dijk, R. Teske, W.I. van de Lageweg, M.G. Kleinhans, W.R.R. 49, 7558 (2013)

5. A. Vegas-Lunam, A. Crosato, W.S.J. Uijttewaal, Ear. Sur. Proc. Land. 40, 157 (2015) 